\title{
Mitochondrial APE1 promotes cisplatin resistance by downregulating ROS in osteosarcoma
}

\author{
YUFENG LIU, ZHIMIN ZHANG, QING LI, LIANG ZHANG, YI CHENG and ZHAOYANG ZHONG \\ Cancer Center, Daping Hospital, Army Medical University (Third Military Medical University), \\ Chongqing 400038, P.R. China
}

Received October 14, 2019; Accepted April 22, 2020

DOI: $10.3892 /$ or.2020.7633

\begin{abstract}
Apurinic/apyrimidinic endonuclease 1 (APE1) is a primary nuclear-localized multifunctional protein in osteosarcoma. However, the cytoplasmic localization of APE1 was found to be functional and to increase with cisplatin resistance, yet the molecular mechanism is unknown. In the present study, we explored the cisplatin resistance mechanism in osteosarcoma from the new perspective of APE1 extranuclear biological activity. Using cisplatin-resistant and cisplatin-sensitive osteosarcoma cell lines, we found that mitochondrial APE1 (mtAPE1) was overexpressed in cisplatin-resistant cells but not in sensitive cells. Overexpression of mtAPE1 reduced cisplatin-induced apoptosis, while knockdown of APE1 reversed this phenomenon and caused oxidative DNA damage via overproduction of reactive oxygen species (ROS). We further demonstrated that high mtAPE1 expression could downregulate ROS production by decreasing the phosphorylation of Rac1 (p-Rac1), further promoting cisplatin resistance in osteosarcoma. Our findings suggest that mitochondrial APE1 promotes cisplatin resistance by decreasing ROS generation, which may provide new ideas for researching the molecular mechanism of osteosarcoma chemoresistance and strategies to overcome cisplatin resistance in osteosarcoma.
\end{abstract}

\section{Introduction}

Osteosarcoma is a frequent primary cancer of bone in adolescents (1), and neoadjuvant chemotherapy followed by surgery has led to a $60-70 \%$ 5-year survival rate. However, the survival rate has not further improved over the last two decades (2), mainly due to the resistance of patients to chemotherapy.

Correspondence to: Professor Zhaoyang Zhong, Cancer Center, Daping Hospital, Army Medical University (Third Military Medical University), 10 Changjiang Zhilu, Daping Yuzhong, Chongqing 400038, P.R. China

E-mail: zhongzhaoyang08@hotmail.com

Key words: apurinic/apyrimidinic endonuclease 1 (APE1), mitochondria, reactive oxygen species, ROS, chemoresistance, osteosarcoma
Cisplatin is broadly used for osteosarcoma chemotherapy, and cisplatin resistance is common in osteosarcoma patients $(3,4)$. In addition to crosslinking with nuclear DNA (nDNA) and thus inducing genomic DNA damage, cisplatin also cytotoxically results in tumor cell apoptosis via the production of ROS (5). In fact, a previous study showed that inhibition of ROS production could block the antitumor effect of chemotherapeutic drugs (6). Apurinic/apyrimidinic endonuclease 1 (APE1) is involved in the toxic effects of many chemotherapeutic agents $(7,8)$, and extranuclear APE1 plays a role in the ROS regulation of apoptosis and responses to oxidative stress (9-11). Thus, this strategy may become another promising research direction for overcoming chemotherapy resistance.

As a multifunctional protein, APE1 has both DNA repair and redox functions in mammals and is involved in oxidative stress, ROS regulation, and tumorigenesis (12-16). APE1 is primarily localized in the nucleus, but nuclear/cytoplasmic coexpression patterns are common in various tumors, and markedly high cytoplasmic APE1 expression is associated with poor prognosis (17-19). In a previous study, APE1 cytoplasmic transport from the nucleus was observed after cisplatin treatment in osteosarcoma cells, and cytoplasmic APE1 expression was increased in cases of cisplatin resistance and poor prognosis. This subcellular alteration may contribute to the protection of cells and reduction in the extent of mitochondrial DNA (mtDNA) damage. We further confirmed that APE1 exhibited mitochondrial-targeted localization (MTS) within residues 289-318 in its C terminus by analyzing truncated subcellular-targeted APE1 constructs (20). We also found that APE1 mitochondrial transport inhibited cell apoptosis after ROS stimulation in lung cancer (21). These findings suggest that APE1 in mitochondria is significant and worth studying; however, little is known about the specific role of mitochondrial-localized APE1.

The main sources of cellular ROS are mitochondria and NADPH oxidases (6). APE1 in mitochondria could regulate genes encoding the mitochondrial electron transport chain (ETC) and further suppress apoptosis; furthermore, the ETC is the main source of ROS in mitochondria (22). Another study indicated that cytoplasmic APE1 could suppress intracellular ROS production in endothelial cells through modulation of Rac1-regulated NADPH oxidase (10). Altogether, these data suggest that cytoplasmic APE1 and osteosarcoma chemotherapy resistance are closely related and that APE1 
in mitochondria may play an essential role. Therefore, we hypothesized that the high mitochondrial expression of APE1 downregulates ROS levels and further promotes cisplatin resistance in osteosarcoma.

In this study, we tested the hypothesis that high mtAPE1 expression could protect cells from cisplatin-induced apoptosis. Our results showed that APE1 translocated from the nucleus to the mitochondria in cisplatin-resistant osteosarcoma cell lines. In addition, overexpression of mtAPE1 enhanced the survival of cells after cisplatin treatment by decreasing ROS production via $\mathrm{p}$-Rac1. In contrast, apoptosis, overproduction of ROS and DNA damage were observed in APE1-deficient cells. Our findings suggest that targeting APE1 could ameliorate the response of cisplatin-resistant cells to cisplatin treatment via overproduction of ROS, which may provide a new strategy to overcome cisplatin resistance in osteosarcoma.

\section{Materials and methods}

Human osteosarcoma tissues. A total of 7 osteosarcoma tissues were obtained from patients with osteosarcoma at Daping Hospital (Chongqing, China). The 7 patients included 3 males and 4 females, aged 9-52 years with an average age of 31 years. The tumor tissue was collected between November 2016 and December 2018. We evaluated the therapeutic effect of platinum drugs and divided patients into: i) complete response (CR): All target lesions completely disappeared and was maintained for at least 4 weeks; ii) partial response (PR): The sum of the maximum diameter of the baseline lesions was reduced by more than $30 \%$, and it was maintained for at least 4 weeks; and iii) progressive disease (PD): The sum of the maximum diameter of the baseline lesions was increased by more than $20 \%$ or new lesions appeared. Our study was performed with the approval of the Ethics Committee of Daping Hospital (Chongqing, China), and informed consent was obtained from each patient.

Cell lines and cell culture. The human osteosarcoma lines U2OS, SAOS2, MG-63 and HOS were purchased from the American Type Culture Collection (Manassas, VA, USA), and U2OS(R) was donated by Professor Xi Wei (Cancer Hospital, Tianjin, China). 9901 and 9607 cells were donated by Profressor Qingyu Fan (Fourth Military Medical University, Xian, China). All the cells were cultured in Dulbecco's modified Eagle's medium (DMEM; Invitrogen; Thermo Fisher Scientific, Inc.) containing 10\% (v/v) fetal bovine serum (FBS; Invitrogen; Thermo Fisher Scientific, Inc.) and 1\% (v/v) penicillin/streptomycin (Invitrogen; Thermo Fisher Scientific, Inc.) at $37^{\circ} \mathrm{C}$ and $5 \% \mathrm{CO}_{2}$.

Transfection. A full-length deleted APE1 expression vector (shRNA-APE1) and mitochondrial-targeted truncated APE1 (C-terminal sequence including residues 289-318; mtAPE1) lentivirus were purchased from Genechem Corporation. For shRNA-APE1, we performed two different sequence interferences, and we chose the one that was mose effective. The chosen vector shAPE1 carrying the human APE1 siRNA sequence, was designed and validated as in previous studies (23-26). The chosen sequences are antisense (5'-GUCUGGUACGACUGG AGUACC-3', 5'-UACUCCAGUCGUACCAGACCU-3') and nonsense (5'-CCAUGAGGUCAGCAUGGUCUG-3', 5'-GAC CAUGCUGACCUCAUGGAA-3'). Cells were incubated with shRNA-APE1 or mtAPE1 transfection complexes at $30 \%$ confluence for $48-72 \mathrm{~h}$ and then treated with $3 \mu \mathrm{g} / \mathrm{ml}$ puromycin (Invitrogen; Thermo Fisher Scientific, Inc.). After 48 h, cells were harvested for subsequent experiments.

Cell viability assay. Cells were seeded in a 96-well plate at $4 \times 10^{3}$ cells/well and incubated in $5 \% \mathrm{CO}_{2}$ at $37^{\circ} \mathrm{C}$ overnight. Then, the cells were treated with the indicated concentration of cisplatin and incubated for $48 \mathrm{~h}$. DMEM supplemented with 10\% (v/v) CCK-8 (C0121; Beyotime Institute of Biotechnology) reagent was added to each well after cisplatin treatment, followed by another $2 \mathrm{~h}$ of incubation, and the optical density (OD) was then measured at $450 \mathrm{~nm}$ and analyzed with SPSS software 20.0 (IBM Corp.).

Immunofluorescence. Cells were seeded on a slide at $40 \%$ confluence/well in a 6-well plate. After washing twice, 250 nM MitoTracker Red CMXRos probe (Molecular Probe) was added and incubated for another $30 \mathrm{~min}$ at $37^{\circ} \mathrm{C}$. Cells were fixed with $4 \%$ paraformaldehyde (w/v) in PBS for $30 \mathrm{~min}$ at room temperature (RT), and $0.25 \%$ Triton (v/v) PBS was added and incubated at $37^{\circ} \mathrm{C}$ for $30 \mathrm{~min}$. The samples were cultured in anti-APE1 (mouse monoclonal, cat. no. 17774, dilution 1:500; Santa Cruz Biotechnology, Inc) at $4^{\circ} \mathrm{C}$ overnight. After washing, the cells were incubated with a secondary antibody conjugated to fluorescein isothiocyanate (FITC) (dilution 1:400, cat. no. 11426320001; Roche) or DyLight 405 (dilution 1:400, cat. no. A23120; Abbkine) at $37^{\circ} \mathrm{C}$ for $1 \mathrm{~h}$. Then, the cells were stained with or without DAPI nuclear probe (dilution 1:400, cat. no. 10236276001; Roche) at RT for 2 min. After drying and fixation, the samples were visualized with fluorescence microscope.

Western blot analysis. Nuclear, cytoplasmic, and mitochondrial proteins were isolated from osteosarcoma cells using nuclear and cytoplasmic protein extraction kits (P0028, Beyotime Institute of Biotechnology) and mitochondria isolation kits (89874, Pierce Biotechnology; Thermo Fisher Scientific, Inc.) according to the manufacturer's protocol. Proteins were electrophoresed by $12 \%$ SDS-PAGE, transferred to polyvinylidene difluoride (PVDF) membranes, and blocked with TBST containing $10 \%$ (w/v) nonfat milk at $37^{\circ} \mathrm{C}$ for $1 \mathrm{~h}$. The membranes were incubated with primary antibodies at $4^{\circ} \mathrm{C}$ overnight and then with the secondary antibody (dilution 1:5,000, cat. no. ab6721, ab205719; Abcam) at RT for $2 \mathrm{~h}$. After washing, the membranes were reacted with chemiluminescent reagents, and proteins were visualized with the ChemiDoc $^{\mathrm{TM}}$ Touch Imaging System and analyzed by Image Lab software (Bio-Rad Laboratories, Inc.).

The dilution ratios and manufacturers' information for the primary antibodies are as follows: Anti-APE1 (mouse monoclonal, cat. no. 17774, dilution 1:5,000; Santa Cruz Biotechnology, Inc.); anti-ku80 (rabbit monoclonal, cat. no. ab80592, dilution 1:3,000; Abcam); anti-tubulin (rabbit monoclonal, cat. no. 2128, dilution 1:1,000; Cell Signaling Technology, Inc.); anti-COX IV (rabbit monoclonal, cat. no. 4850, dilution 1:3,000; Cell Signaling Technology, Inc.); anti-p-Rac 1, (rabbit monoclonal, cat. no. 2461, dilution 
1:1,000; Cell Signaling Technology, Inc.); anti-Rac 1 (rabbit polyclonal, cat. no. 4651, dilution 1:1,000; Cell Signaling Technology, Inc.); anti- $\gamma-\mathrm{H} 2 \mathrm{AX}$ (rabbit monoclonal, cat. no. 9718, dilution 1:1,000; Cell Signaling Technology, Inc.) and anti-cleaved PARP (rabbit monoclonal, cat. no. ab32064, dilution 1:1,000; Abcam). Anti- $\beta$-tubulin antibody was used as a general or cytoplasmic fraction loading control. Anti-COX IV antibody and anti-ku80 antibody were used as mitochondrial and nuclear fraction loading control, respectively.

Immunohistochemistry (IHC) analysis. IHC was performed as described previously (18). Briefly, after deparaffinization and blocking, sections were incubated with primary antibodies at $4^{\circ} \mathrm{C}$ overnight. After washing with PBS, the sections were incubated with a secondary antibody for $1 \mathrm{~h}$ at RT. Then, 3,3'-diaminobenzidine (DAB) substrate was used to develop color, and hematoxylin was used for counterstaining. The primary antibodies were anti-APE1 (mouse monoclonal, cat. no. 17774, dilution 1:500; Santa Cruz Biotechnology, Inc.) and anti- $\gamma$-H2AX (rabbit monoclonal, cat. no. 9718, dilution 1:50; Cell Signaling Technology, Inc.).

ROS production measurement. ROS production was measured using a reactive oxygen species assay kit (DCFH-DA, S0033; Beyotime Institute of Biotechnology or DHE, Beibo Biotechnology, Shanghai, China) according to the manufacturer's instructions. Briefly, osteosarcoma cells were plated in 6-well plates and then treated with the indicated DMSO, cisplatin, and $\mathrm{H}_{2} \mathrm{O}_{2}$. After incubation at $37^{\circ} \mathrm{C}$ for the indicated time, the old culture medium was removed, and 1:1,000 (v/v) DCFH-DA/DHE in serum-free medium was added, followed by incubation for another $30 \mathrm{~min}$ at $37^{\circ} \mathrm{C}$. After washing three times with PBS, the cells were collected and immediately analyzed by flow cytometry.

Apoptosis analysis. Osteosarcoma cells were plated in 6-well plates and then treated with the indicated concentration of cisplatin for $48 \mathrm{~h}$ in $5 \% \mathrm{CO}_{2}$ at $37^{\circ} \mathrm{C}$. A solution of FITC Annexin $\mathrm{V}$ and propidium iodide (PI) (BD Biosciences) was added to the cultures, which were incubated for $15 \mathrm{~min}$ at RT. Then, the cells were collected and immediately analyzed by flow cytometry.

Statistical analysis. Statistical analysis was performed with SPSS 20.0 (IBM Corp.) and GraphPad Prism 5.0 software (GraphPad Software, Inc.). Statistical tests included independent samples t-test. and one-way ANOVA (Tukey) test. $\mathrm{P}<0.05$ was considered statistically significant.

\section{Results}

APE1 alteration in cisplatin-resistant osteosarcoma cells. As a critical factor mediating cancers, the expression and localization of APE1 have an intimate connection with chemotherapy resistance. Based on the moderate APE1 expression and medium sensitivity to cisplatin (Fig. S1A and B), U2OS cells were chosen as the parent to construct a cisplatin-resistant osteosarcoma cell line named U2OS(R) through a dose escalation method. CCK-8 and apoptosis data demonstrated that the cisplatin-resistant osteosarcoma cell line were successfully established (Fig. 1A-C). The cisplatin half maximal inhibitory concentration $\left(\mathrm{IC}_{50}\right)$ of $\mathrm{U} 2 \mathrm{OS}(\mathrm{R})$ cells was approximately 3 -fold higher than that of the parental cells $(8.16 \mu \mathrm{g} / \mathrm{ml}$ vs. $2.57 \mu \mathrm{g} / \mathrm{ml}$ ). To further test the connection between APE1 expression and cisplatin resistance, western blotting showed the elevated total APE1 (tAPE1) levels in U2OS(R) cells. These results suggest that APE1 expression may increase with cisplatin resistance in osteosarcoma cells.

APE1 translocates to mitochondria in cisplatin-resistant osteosarcoma cells. To test our hypothesis that APE1 mitochondrial transport could induce cisplatin resistance, we next assessed whether mitochondrial APE1 expression was altered in parental cells following cisplatin treatment by western blot and immunofluorescence assays. The results showed that the mtAPE1 level was upregulated after cisplatin treatment in a time- and dose-dependent manner (Fig. 2A). Consistent with the western blot results, the immunofluorescence assay showed an enhanced mitochondrial APE1 (mtAPE1) signal after cisplatin treatment (Fig. 2B). These results indicated that mtAPE1 may play a protective role in cisplatin resistance. To further confirm the effect of mtAPE1 and explore the APE1 expression differences in U2OS and U2OS(R) cells, purified nuclear, cytoplasmic, and mitochondrial extracts were prepared for western blotting. The results showed that APE1 was mainly located in the nucleus in both cell lines. Elevated mtAPE1 and cytoplasmic APE1 (cAPE1) levels were observed in the U2OS(R) cells. Interestingly, a slight decrease in nuclear APE1 (nAPE1) expression was observed in the U2OS(R) cells, which indicated that APE1 translocated from the nucleus to mitochondria and was overexpressed in U2OS(R) cells. Mitochondrial APE1 may play a crucial role in cisplatin resistance, more so than nuclear APE1 (Fig. 2C). To further confirm the results, an immunofluorescence assay was used to trace the distribution of the APE1 protein. Nuclear and nuclear/cytoplasmic APE1 staining was observed in both U2OS and U2OS(R) cells. Notably, the mtAPE1 signal in U2OS(R) cells was much stronger than that in U2OS cells (Fig. 2D). Taken together with the findings shown in Figs. 1 and 2, these results suggest that high APE1 expression and mtAPE1 are involved in the cisplatin resistance of osteosarcoma cells, especially the increased mitochondrial APE1 expression.

APE1 knockdown restores the response to cisplatin in cisplatin-resistant osteosarcoma cells. To further test the correlation between APE1 expression and cisplatin resistance, we examined whether knockdown of APE1 could promote cisplatin-induced apoptosis. In this study, we chosen the shAPE1 vector carrying the human APE1 siRNA sequence, which was designed and validated in previous studies (23-26). We chose the interference sequence that worked best in this research. Apoptosis was measured by cleaved PARP and $\gamma$-H2AX. Western blot analysis showed that the APE1 levels were decreased in U2OS, U2OS(R) and SAOS2 cells. Apoptosis with more DNA damage was observed after cisplatin treatment in the APE1-deficient cells. Due to its base repair function, high expression of APE1 could protect cells from cisplatin by reducing DNA damage (Fig. 3A). Furthermore, immunofluorescence also showed slight APE1 staining in both APE1-knockdown U2OS and U2OS(R) cells 

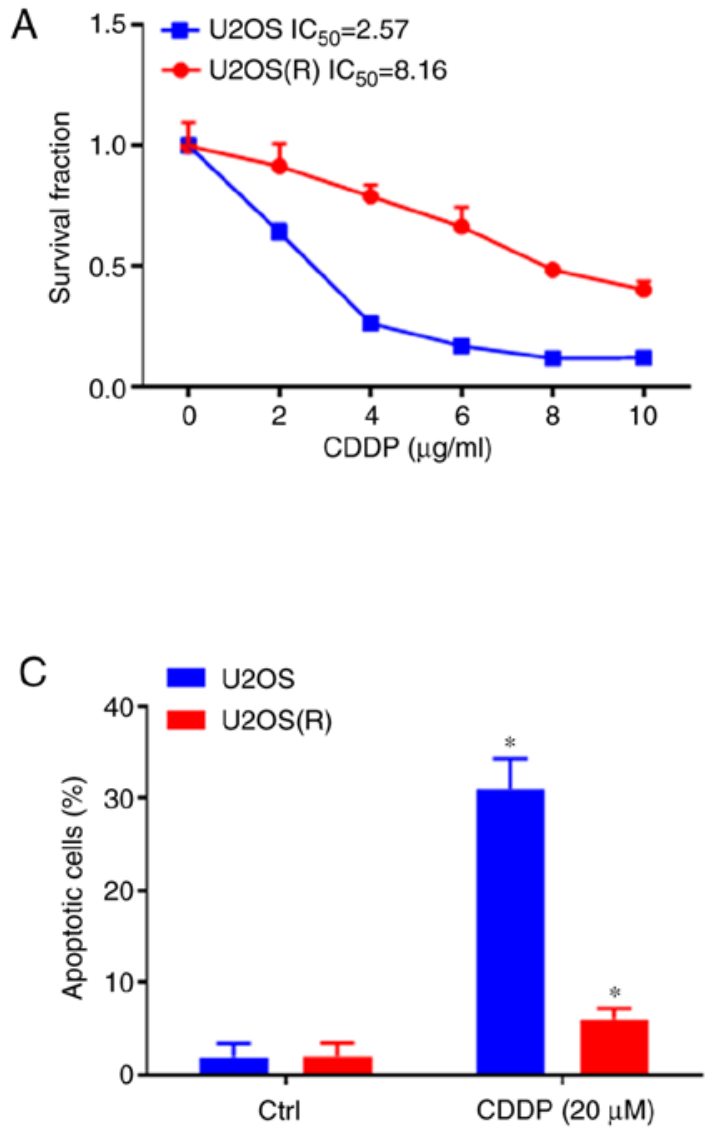

B
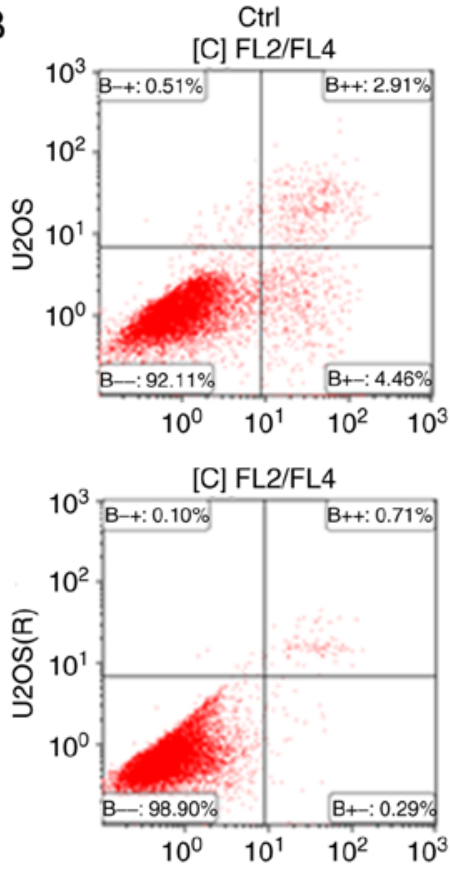

CDDP

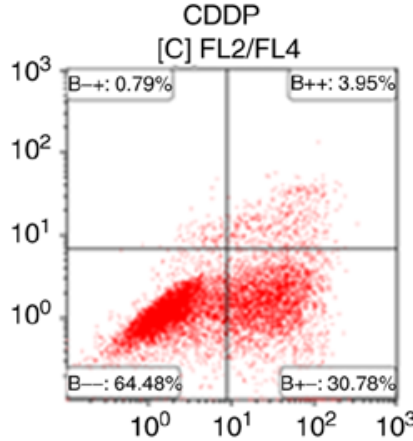

[C] FL2/FL4

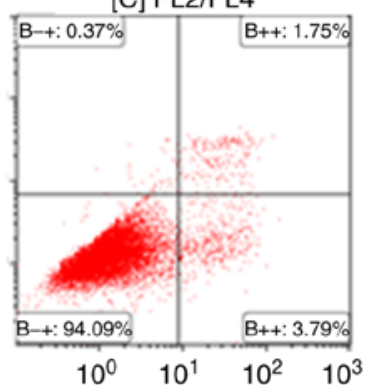

D

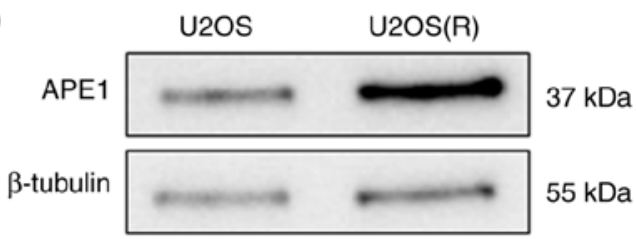

Figure 1. APE1 alteration in cisplatin-resistant osteosarcoma cells. (A) The CCK-8 assay shows successful establishment of U2OS(R) cells. The cells were treated with different concentrations of cisplatin for $48 \mathrm{~h}$, and the $\mathrm{IC}_{50}$ of each cell line was then determined using SPSS software. (B) U2OS and U2OS(R) cells were treated with or without $20 \mu \mathrm{M}$ cisplatin for $48 \mathrm{~h}$ and then collected and subjected to flow cytometry. (C) Apoptosis data were processed by GraphPad Prism 6 software. (D) Western blot analysis shows APE1 expression changes in U2OS(R) cells. Anti- $\beta$-tubulin antibody was used as loading control. *P<0.05, statistically significant from the untreated control. CDDP, cisplatin; APE1, apurinic/apyrimidinic endonuclease 1 ; $\mathrm{IC}_{50}$, half maximal inhibitory concentration.

(Fig. 3B). Interestingly, a small amount of cytoplasmic APE1 was observed in the $\mathrm{U} 2 \mathrm{OS}(\mathrm{R})$ cells, in contrast to the predominantly nuclear APE1 in U2OS cells. The CCK-8 assay was used to test whether APE1 knockdown could promote cisplatin-induced apoptosis (Fig. 3C). We found that knockdown of APE1 restored the response to cisplatin in the U2OS, U2OS(R) and SAOS2 cells, especially in cisplatin-resistant cells. The $\mathrm{IC}_{50}$ value of U2OS(R) siAPE1 was still higher than that of $\mathrm{U} 2 \mathrm{OS}(3.37 \mu \mathrm{g} / \mathrm{ml} \mathrm{vs} .1 .14 \mu \mathrm{g} / \mathrm{ml})$, which may have contributed to the remaining cytoplasmic APE1. Taken together with the findings above, these results strongly indicate that elevated APE1 expression, especially that in the mitochondria, plays a key role in protecting cells from cisplatin-induced apoptosis. Furthermore, these results suggest that APE1 downregulation is an effective approach to restore sensitivity to cisplatin in cisplatin-resistant osteosarcoma cells.

Mitochondrial APE1 overexpression enhances cisplatin resistance in parental cells. To further clarify the effect of mitochondrial APE1 on cisplatin resistance, we constructed an mtAPE1 overexpression model using a mitochondrial-targeted truncated APE1 vector transfected into U2OS and SAOS2 cells. Western blotting was used to detect mtAPE1 and nAPE1 levels with or without cisplatin treatment (Fig. 4A). Interestingly, mtAPE1 expression increased after cisplatin treatment, especially in the mtAPE1-transfected groups, while nAPE1 expression decreased. These results suggest that mitochondrial APE1 plays a protective role in the response to cisplatin. Immunofluorescence assays showed strong staining of mitochondrial APE1 in the mtAPE1-transfected groups compared to the control group (Fig. 4B). These results indicated that we successfully constructed mitochondrial overexpression groups. The CCK-8 assay was used to test the protective effects after cisplatin treatment (Fig. 4C). We found that overexpression of mtAPE1 could reduce apoptosis induced by cisplatin in U2OS and SAOS2 cells, and the effect was comparable to that in U2OS(R) cells. These results strongly indicated that APE1 mitochondrial transport and overexpression play crucial roles in the resistance of osteosarcoma cells to cisplatin.

Mitochondrial APE1 overexpression enhances cisplatin resistance by inhibiting ROS production. To test our hypothesis 
A

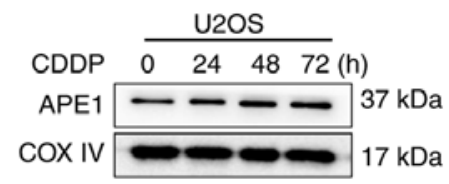

B

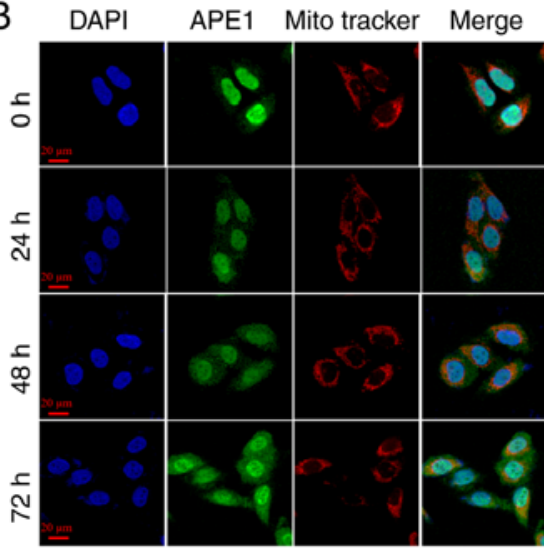

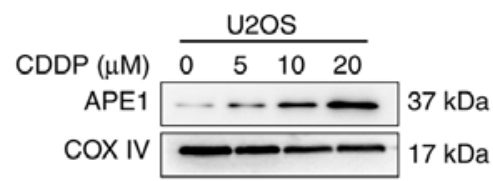

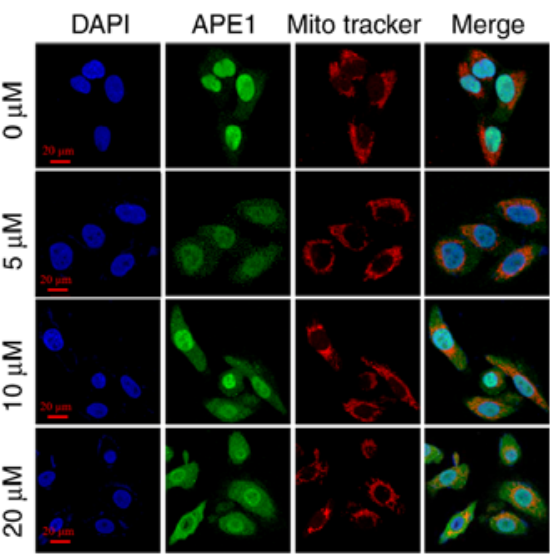

C
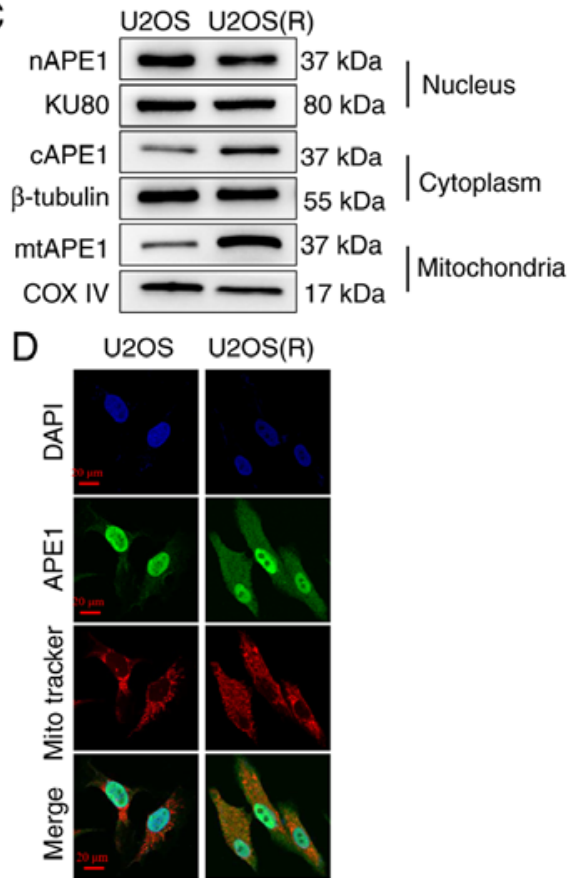

Figure 2. APE1 translocates to the mitochondria in cisplatin-resistant osteosarcoma cells. (A) U2OS cells were treated with $10 \mu \mathrm{M}$ cisplatin (CDDP) for 0 , 24,48 or $72 \mathrm{~h}$ or treated with CDDP at $0,5,10$ or $20 \mu \mathrm{M}$ for $24 \mathrm{~h}$. Then, purified mitochondrial proteins were prepared and subjected to western blotting with anti-APE1 antibody. Anti- $\beta$-tubulin antibody, anti-COX IV antibody and anti-KU80 antibody were used as cytoplasmic, mitochondrial and nuclear fraction loading control, respectively. (B) After the same treatment as that described in A, the cellular distribution of APE1 in U2OS cells was detected by immunofluorescence assay. FITC-conjugated (green), MitoTracker (red), and DAPI (blue) antibodies were used to visualize APE1, mitochondria, and nuclei, respectively. The mitochondrial APE1 is shown as yellow-orange. (C) Purified nuclear (nAPE1), cytoplasmic (cAPE1), and mitochondrial (mtAPE1) proteins of U2OS and $\mathrm{U} 2 \mathrm{OS}(\mathrm{R})$ cells were prepared and subjected to western blot analysis. Anti-KU80, $\beta$-tubulin and COXIV represent the nucleus, cytoplasm, and mitochondria, respectively. (D) The cellular distribution of APE1 in U2OS and U2OS(R) cells was determined by the immunofluorescence assay. APE1, apurinic/apyrimidinic endonuclease 1 .
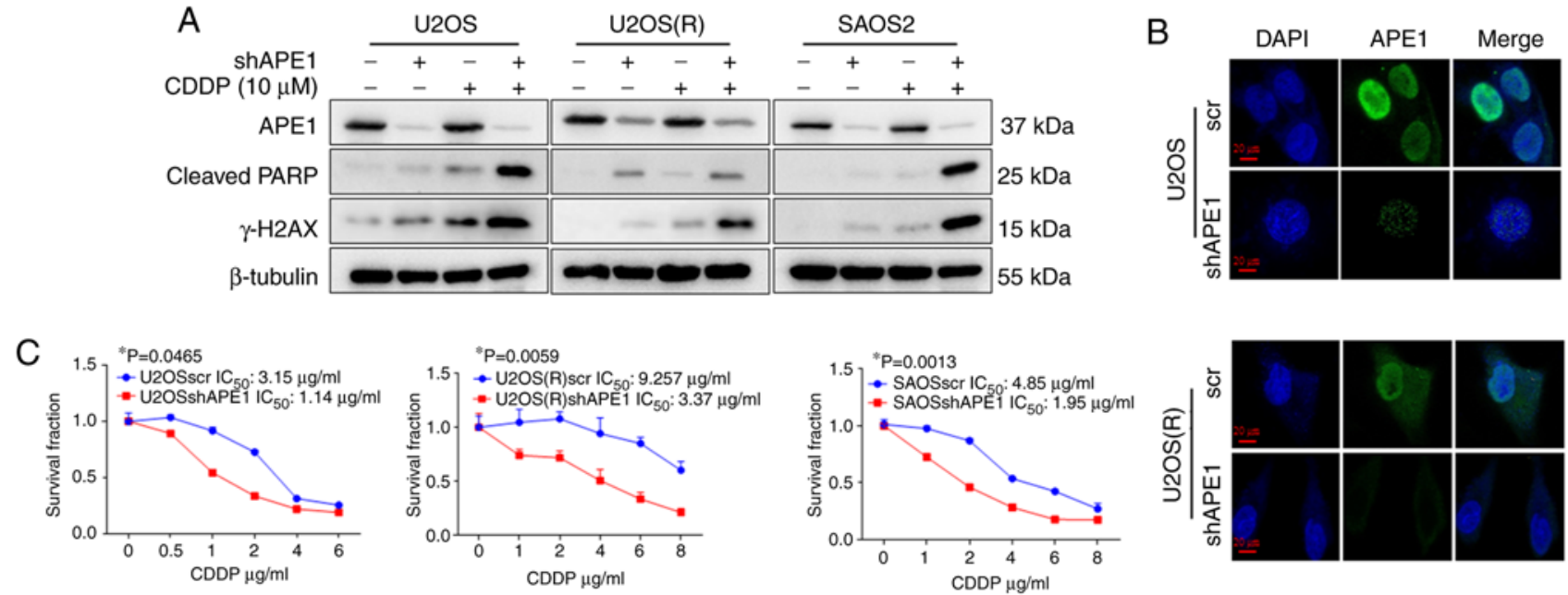

Figure 3. APE1 knockdown restores the response to cisplatin in cisplatin-resistant osteosarcoma cells. (A) After shAPE1 lentiviral infection in U2OS, U2OS(R), and SAOS2 cells, the cells were treated with or without $10 \mu \mathrm{M}$ cisplatin (CDDP) for $24 \mathrm{~h}$ and then subjected to western blot analysis with an APE1 antibody, cleaved PARP antibody, and $\gamma$-H2AX antibody. Anti- $\beta$-tubulin antibody was used as loading control. (B) The expression and distribution of APE1 in U2OS and $\mathrm{U} 2 \mathrm{OS}(\mathrm{R})$ cells was detected by an immunofluorescence assay and observed under a laser confocal microscope. A DAPI (blue) antibody and FITC-conjugated (green) antibody were used to visualize the APE1 protein. (C) The CCK-8 assay was used to assess cisplatin cytotoxicity after knockdown of APE1 (shAPE1) in U2OS, U2OS(R) and SAOS2 cells. The cell lines were treated with different concentrations of cisplatin for $48 \mathrm{~h}$, and the $\mathrm{IC}_{50}$ of each cell line was then determined using SPSS software. ${ }^{*} \mathrm{P}<0.05$, statistically significant from the vector alone transfected control. $\mathrm{IC}_{50}$, half maximal inhibitory concentration; APE1, apurinic/apyrimidinic endonuclease 1.

that high expression of mtAPE1 downregulates ROS levels and further promotes drug resistance in osteosarcoma chemotherapy, we investigated the effect of cell models on cisplatin- or oxidative agent-induced apoptosis and ROS production. The U2OS, U2OS(R), APE1-deficient (shAPE1) and mtAPE1-transfected groups were treated with DMSO, 
A
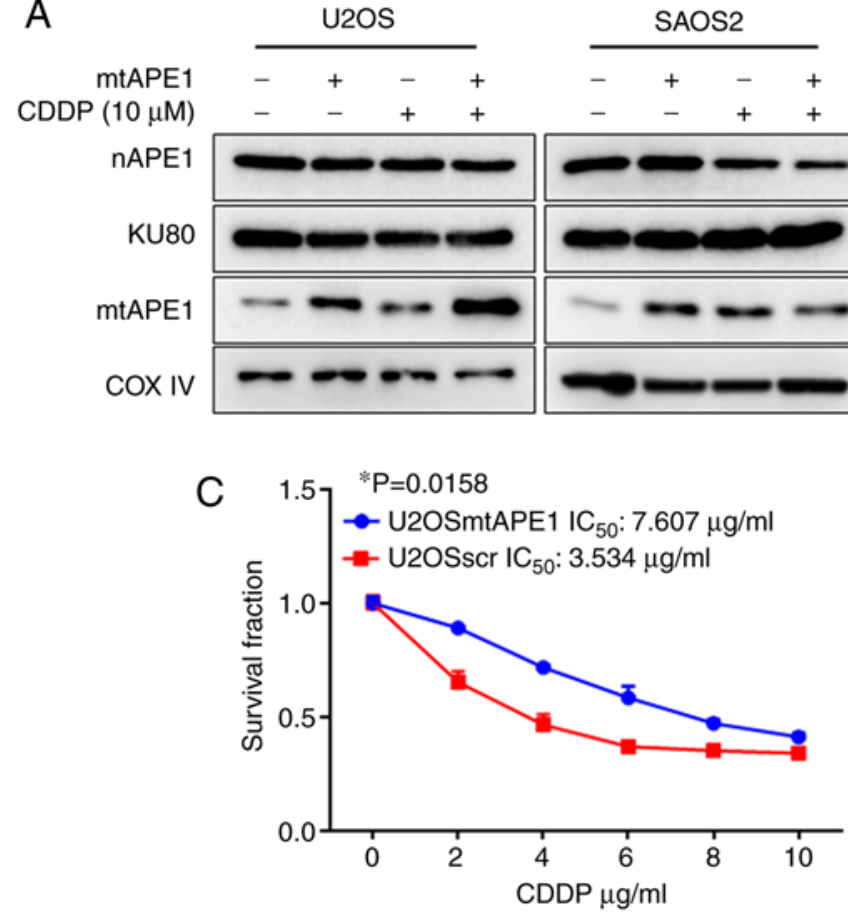

B

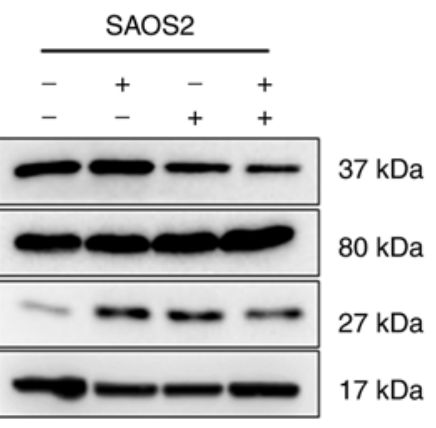

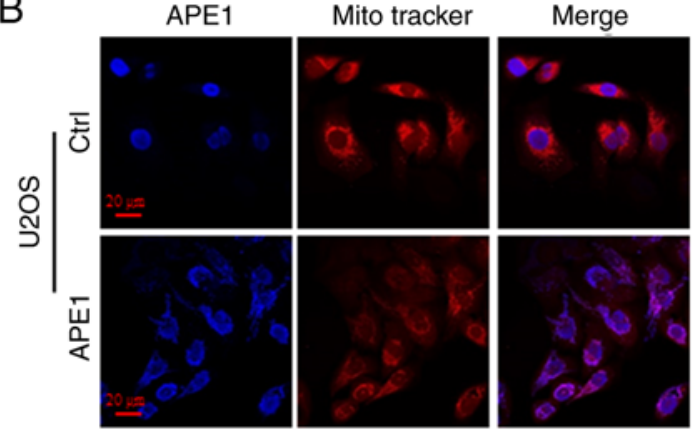

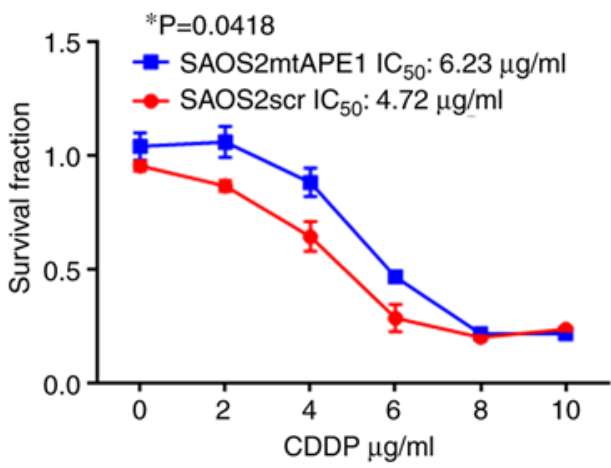

Figure 4. Mitochondrial APE1 overexpression enhances cisplatin resistance in parental cells. (A) After mitochondrial APE1 (mtAPE1) vector transfection in U2OS and SAOS2 cells, the cells were treated with or without $10 \mu \mathrm{M}$ cisplatin (CDDP) for $24 \mathrm{~h}$. Then, western blot analysis was used to assess mtAPE1 and nuclear APE1 (nAPE1) levels. Anti-COX IV antibody and anti-KU80 antibody were used as mitochondrial and nuclear fraction loading control, respectively. (B) The expression and distribution of APE1 in U2OSscr and U2OSmtAPE1 cells was detected by immunofluorescence assays and observed under a laser confocal microscope. MitoTracker (red) and APE1 (blue) antibodies were used to visualize mitochondria and the APE1 protein, respectively. The localization of APE1 in mitochondria is shown in purple. (C) The CCK-8 assay was used to assess cisplatin cytotoxicity after mitochondrial APE1 overexpression in U2OS and SAOS 2 cells. "P<0.05, statistically significant from the vector alone transfected control. APE1, apurinic/apyrimidinic endonuclease 1.

cisplatin, or hydrogen peroxide, and ROS production was measured and analyzed by flow cytometry (Fig. 5A). ROS production was significantly high in cisplatin-sensitive osteosarcoma cells but not in cisplatin-resistant osteosarcoma cells. Conversely, ROS overproduction was found in APE1-deficient models in both U2OS and U2OS(R) cells. mtAPE1 overexpression significantly inhibited ROS production. These results indicated that cisplatin could induce the overproduction of ROS in cisplatin-sensitive osteosarcoma cells and that targeted APE1 could induce ROS production in cisplatin-resistant osteosarcoma cells. Studies have shown that p-Racl can promote ROS production, and we next tested whether p-Racl plays a key role in cisplatin-induced ROS production in osteosarcoma. Apoptosis was also measured by cleaved PARP. p-Rac1 expression was lower in the U2OS(R) and U2OSmtAPE1 cells than in the other cell lines. We also found that shAPE1 did not work effectively in the U2O2(R) cell line, and due to the insufficient APE1 knockdown level in $\mathrm{U} 2 \mathrm{O} 2(\mathrm{R})$, the increase of cleaved PARP was not obvious. In contrast, the knockdown level of U2OS reached a certain level, and the expression of cleaved PARP could be obviously increased (Fig. 5B). As shown in Fig. 5B and C, cisplatin induced the production of p-Racl and cleaved PARP, the levels of which were higher in APE1-deficient cells than in mtAPE1-transfected cells. The results indicated that mtAPE1 overexpression could downregulate ROS production by decreasing p-Rac1 and reducing apoptosis after oxidative agent treatment in osteosarcoma cells. Conversely, knockdown of APE1 could result in the overproduction of ROS, further promoting cisplatin-induced cell apoptosis.

We next tested whether ROS overproduction was due to cisplatin-induced apoptosis by measuring cleaved PARP and $\gamma$-H2AX. N-Acetyl cysteine (NAC) is an antioxidant that can partially remove the ROS production induced by cisplatin or hydrogen peroxide in osteosarcoma cells, which was confirmed by the results shown in Fig. 5D. Consistently, NAC markedly reduced the apoptosis induced by cisplatin in APE1-deficient cells, which were originally sensitive to cisplatin, and the same protection was found in other osteosarcoma cells (Fig. 5E). Together, these results showed that high mtAPE1 expression could downregulate ROS production by decreasing $\mathrm{p}-\mathrm{Rac1}$ expression and reducing DNA damage, which protects cells from cisplatin-induced apoptosis, further promoting drug resistance in osteosarcoma chemotherapy.

APE1 correlates with cisplatin resistance in clinical samples. To investigate the association between APE1 expression and cisplatin resistance, 7 osteosarcoma tissues were obtained, and APE1 expression was confirmed by western blot analysis. Varied levels of APE1 were observed in all tissues. As an alkylating agent, cisplatin, which has tumor cytotoxicity, induced DNA strand damage and rapid phosphorylation of the nucleosomal histone protein $\mathrm{H} 2 \mathrm{AX}$ at Ser 139. A significant increase in APE1 expression was possibly associated with reduced or loss of $\gamma-\mathrm{H} 2 \mathrm{AX}$ expression, which may have contributed to the DNA repair activity of APE1 (Fig. 6A). 
A
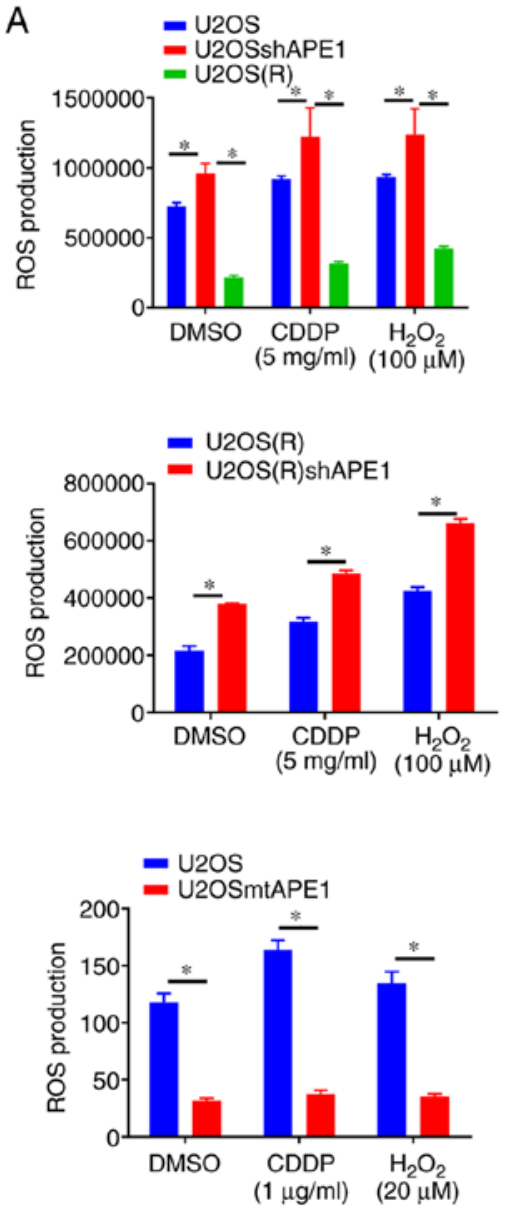

B

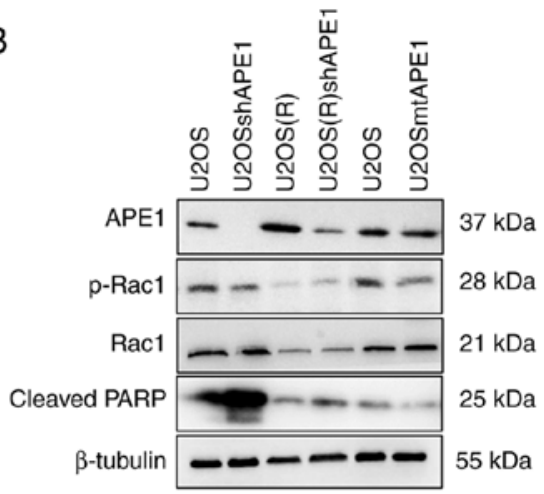

C

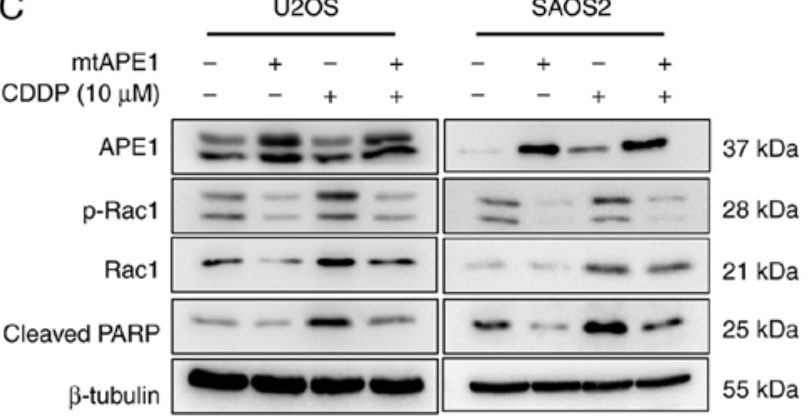

D
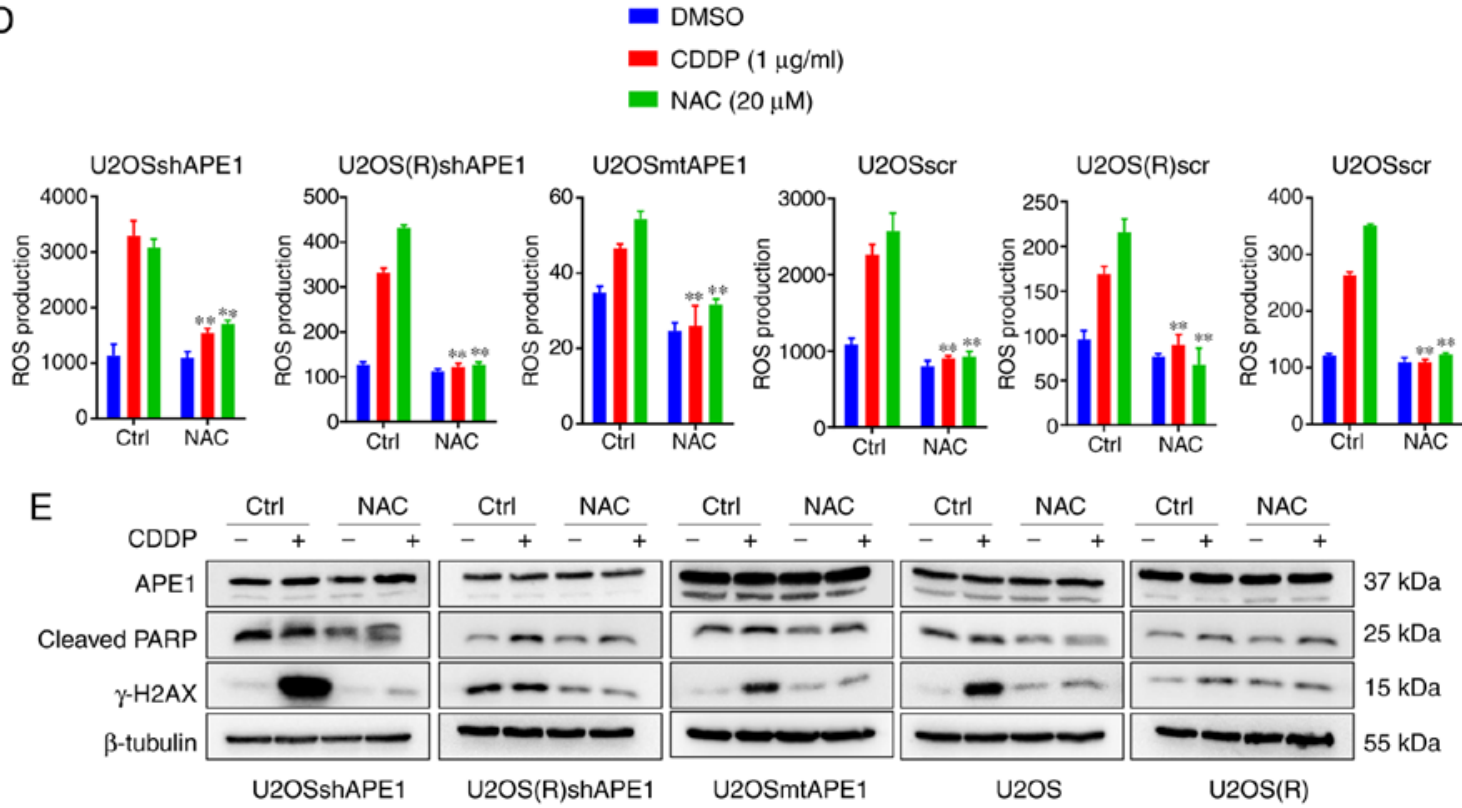

Figure 5. Mitochondrial APE1 (mtAPE1) overexpression enhances cisplatin resistance by inhibiting ROS production. (A) U2OSscr cells, U2OS(R)scr cells, and APE1-deficient cells (U2OSshAPE1; U2OS(R)shAPE1) were treated with DMSO, cisplatin $(5 \mathrm{mg} / \mathrm{ml})$, or hydrogen peroxide $\left(\mathrm{H}_{2} \mathrm{O}_{2}\right)(100 \mu \mathrm{M})$ for $6 \mathrm{~h}$; U2OS and mtAPE1-transfected cells (U2OSmtAPE1) were treated with DMSO, cisplatin (CDDP) $\left(1 \mathrm{mg} / \mathrm{ml}^{\text {) }}\right.$, or $\mathrm{H}_{2} \mathrm{O}_{2}(20 \mu \mathrm{M})$ for $24 \mathrm{~h}$, and ROS production was then measured and analyzed by flow cytometry. (B) Western blot analysis of the cell lines was performed with an APE1 antibody, Rac1 antibody, p-Rac1 antibody, and cleaved PARP antibody. Anti- $\beta$-tubulin antibody was used as loading control. (C) Western blot analysis of U2OSmtAPE1 and SAOS2mtAPE1 cells treated with or without $10 \mu \mathrm{M}$ CDDP for $24 \mathrm{~h}$ was performed with an APE1 antibody, Rac1 antibody, p-Rac1 antibody, and cleaved PARP antibody. Anti- $\beta$-tubulin antibody was used as loading control. (D) U2OSscr, U2OS(R)scr, U2OSshAPE1, U2OS(R)shAPE1, and U2OSmtAPE1 cells were treated with DMEM, cisplatin $(1 \mathrm{mg} / \mathrm{ml})$, or $\mathrm{H}_{2} \mathrm{O}_{2}(20 \mu \mathrm{M})$ with or without $5 \mathrm{mM} \mathrm{N}$-acetyl cysteine (NAC) for $24 \mathrm{~h}$, and ROS production was then measured and analyzed by flow cytometry. (E) After treatment as described in D, the cells were prepared and subjected to western blot analysis with an APE1 antibody, cleaved PARP antibody, and $\gamma$-H2AX antibody and probed with a $\beta$-tubulin antibody as a loading control. ${ }^{*} \mathrm{P}<0.05$, statistically significant from the vector alone transfected control; ${ }^{* *} \mathrm{P}<0.05$, statistically significant from the untreated control. APE1, apurinic/apyrimidinic endonuclease 1; ROS, reactive oxygen species; Rac1, Ras-related C3 botulinum toxin substrate 1; p-, phosphorylated; PARP, poly ADP ribose polymerase. 
Table I. Correlation of APE1 and objective response rate of combination therapy of platinum in osteosarcoma patients.

APE1 expression (patient numbers)

$\mathrm{PR} / \mathrm{CR}$

Overexpression $(4,6,7)$

Low expression $(1,2,3,5)$

0

3

3

APE1, apurinic/apyrimidinic endonuclease 1; PR, partial response; CR, complete response; PD, progressive disease.

A

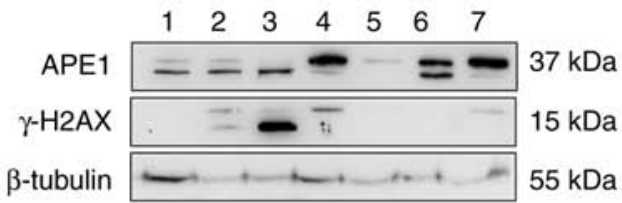

B
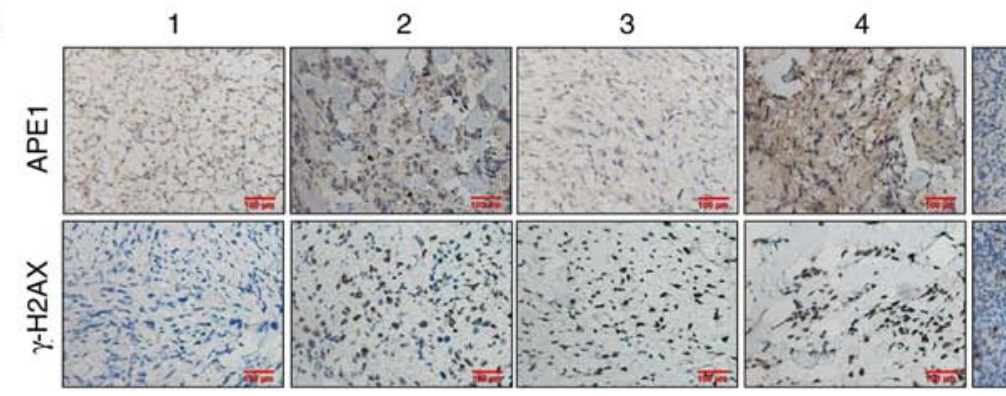

5

6

7

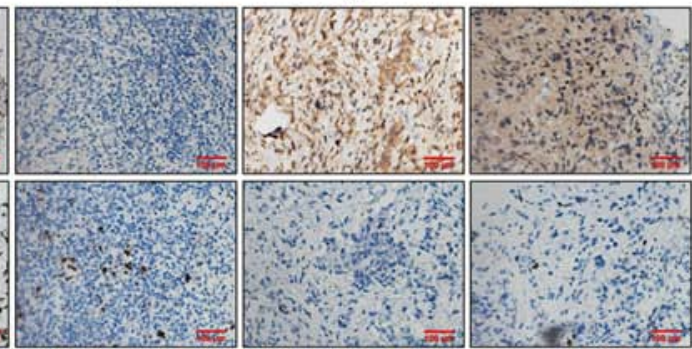

Figure 6. APE1 correlates with cisplatin resistance in clinical samples. (A) Western blot analysis was used to analyze APE1 and $\gamma$-H2AX protein expression in 7 undifferentiated osteosarcoma tissues (1-7). Anti- $\beta$-tubulin antibody was used as loading control. (B) Immunohistochemistry analysis of APE1 and $\gamma$-H2AX in osteosarcoma cells. APE1 was mainly localized in the nucleus and cytoplasm, and $\gamma-\mathrm{H} 2 \mathrm{AX}$ was localized in the nucleus. APE1, apurinic/apyrimidinic endonuclease 1.

Then, we further examined the connection between APE1 and $\gamma$-H2AX in these 7 tumor tissues by immunohistochemistry, revealing that APE1 was mostly negatively correlated with $\gamma$-H2AX (Fig. 6B). As shown in the clinical data (Table I), osteosarcoma patients with high expression of APE1 exhibited a poor prognosis and were more prone to cisplatin resistance. These results indicated that high APE1 expression is associated with a poor prognosis for patients with osteosarcoma patients and with resistance to cisplatin.

\section{Discussion}

In the present study, we tested our hypothesis that high expression of mitochondrial APE1 (mtAPE1) downregulates reactive oxygen species (ROS) levels to further promote cisplatin resistance in osteosarcoma. First, we demonstrated that mtAPE1 expression plays a protective role in cisplatin-resistant osteosarcoma cells, which could be reversed by APE1 deficiency. Next, through mitochondrial-targeted APE1 expression vectors, we explored the mechanism by which mtAPE1 protects osteosarcoma cells from cisplatin-induced apoptosis and found that mtAPE1 could enhance osteosarcoma cell survival after cisplatin treatment by modulating p-Rac1 and then further suppressing intracellular ROS production.

In previous studies, high APE1 expression was associated with chemotherapy resistance in many tumors (13-15), and this resistance could be overcome by the knockdown of APE1. We further found that cisplatin induced APE1 cytoplasmic transport, which increased with chemotherapy resistance in both osteosarcoma cells and clinical samples. In the present study, mtAPE1 expression increased after cisplatin treatment in a time- and dose-dependent manner, and the resistance of osteosarcoma cells to cisplatin was mainly due to mtAPE1 in the cytoplasm. Barchiesi et al demonstrated that Mia40 is responsible for the trafficking of APE1 into the mitochondria (27). We also found that APE1-deficient osteosarcoma cells could promote apoptosis by increasing ROS generation after cisplatin or oxidant agent treatment, and these results were similar to those of previous studies. Vascotto et al found that some redox signaling genes were downregulated in APE1-deficient HeLa cells by a global gene expression assay (28), and this phenomenon may be responsible for the increase in cellular ROS levels in APE1-deficient cells.

The cytotoxicity of cisplatin results in apoptosis via exogenous (death receptor) and endogenous (mitochondrial) pathways, and ROS play a role in both. By causing oxidative damage to nucleic acids, proteins, and lipids, ROS can cause apoptosis or even necrosis. Oxidative DNA damage gives rise to genetic mutations related to tumorigenesis and various pathological conditions. As an essential enzyme in the DNA base excision repair (BER) pathway, APE1 plays a key regulatory role in ROS-induced DNA damage (9). In this study, we showed that $\gamma-\mathrm{H} 2 \mathrm{AX}$ expression was high in the APE1-deficient groups with higher ROS production 
but not in the mtAPE1-transfected or cisplatin-resistant groups with lower ROS levels after cisplatin treatment. These results indicated that ROS overproduction contributed to cisplatin-induced apoptosis in osteosarcoma cells and that mtAPE1 could protect osteosarcoma cells from cisplatin-induced DNA damage and apoptosis by decreasing ROS production.

We further demonstrated that overexpression of mtAPE1 could downregulate ROS production via Racl phosphorylation and further promote drug resistance in osteosarcoma chemotherapy, which further elucidates the mechanism by which APE1 regulates ROS. Many studies have shown that the main sources of cellular ROS are mitochondria and NADPH oxidases $(6,29)$. Oxidative stimulation could cause the stimulation of Racl to regulate the production of ROS in various cell types. Among these is the NADPH oxidase regulated by the ubiquitous small GTPase Rac1 (30-34). Angkeow et al confirmed that cytoplasmic APE1 could regulate p-Rac1 and ROS production to protect endothelial cells from oxidative stress and apoptosis (10). den Hartog et al found that overexpression of APE1 could inhibit p-Rac1 upon reduced ROS generation (9). In addition to the NADPH oxidase complex, the electron transport chain (ETC) is another important cellular source of ROS (35). APE1 regulates the mitochondrial-associated nuclear transcription factors NRF-1 and TFAM through its redox activity, thus mediating ROS production after oxidative stress (22). These data suggest that APE1 in mitochondria plays a crucial role in regulating ROS production. Although our research confirmed that APE1 could regulate ROS expression through phosphorylation of Rac1, it did not directly detect the NADPH activity in response to oxidative stimulation during this process. We did not directly determine the effect of NADPH on ROS in response to oxidative stimulation. This is the limitation of our research, and we will investigate this phenomenon in the future.

The mitochondrial-associated apoptosis pathway is another mechanism of cisplatin cytotoxicity, and mitochondrial function and mtDNA play vital roles in the action of cisplatin $(21,36)$. The protective effect of APE1 in mitochondria may contribute to cisplatin resistance in osteosarcoma (37-39). As Joo et al confirmed, mtAPE1 can stabilize mitochondrial function and protect mouse endothelial cells from protein kinase C (40). Li et al found that the mitochondrial transport of APE1 could suppress photodynamic-induced mitochondrial dysfunction and protect cells (21). In the present study, we found that mtAPE1 expression was increased and protected osteosarcoma cells from cisplatin-induced apoptosis by decreasing ROS production. In addition to our research, mitochondrial function and mtDNA may also participate in cisplatin resistance in osteosarcoma $(41,42)$.

Taken together, our results demonstrated that mitochondrial APE1 plays a crucial role in cisplatin resistance by suppressing ROS generation to further enhance cell survival and that APE1 deficiency could restore the sensitivity of osteosarcoma cells to cisplatin via inducing ROS overproduction. Considering the important role of ROS in chemoresistance, increasing ROS levels could be a novel strategy for overcoming cisplatin resistance in osteosarcoma, which could substantially advance efforts to improve the clinical outcomes of osteosarcoma treatment.

\section{Acknowledgements}

The authors are grateful to Professor Xi Wei and Professor Qingyu Fan for providing the U2OS(R), 9901 and 9607 cell lines. We thank Dr Hualiang Xiao, Dr Zengpeng Li, Ms. Yuxin Yang, Mr. Yi Cheng, and Mr. Linli Zeng, our beloved colleagues of our Pathology and Cancer Center Laboratory, for their technical support.

\section{Funding}

This work was supported by the National Natural Science Foundation of China (NSFC 81372373).

\section{Availability of data and materials}

The datasets used in the present study are available from the corresponding author upon reasonable request.

\section{Authors' contributions}

$\mathrm{ZZ}$ conceived and designed the study. YL was responsible for the experiments and writing the manuscript. The datasets were analyzed by LZ and YC. QL searched and retrieved the relevant literature. $Z Z$ revised the manuscript. All authors read and approved the manuscript and agree to be accountable for all aspects of the research in ensuring that the accuracy or integrity of any part of the work are appropriately investigated and resolved.

\section{Ethics approval and consent to participate}

This human study was approved by the Ethics Committee of Daping Hospital of the Army Medical University (Third Military Medical University, Chongqing, China), and patients provided written informed consent. The research was carried out in accordance with the World Medical Association Declaration of Helsinki.

\section{Patient consent for publication}

Not applicable.

\section{Competing interests}

The authors declare that they have no competing interests.

\section{References}

1. ESMO/European Sarcoma Network Working Group: Bone sarcomas: ESMO Clinical Practice Guidelines for diagnosis, treatment and follow-up. Ann Oncol 25 (Suppl 3): iii113-iii123, 2014.

2. Allison DC, Carney SC, Ahlmann ER, Hendifar A, Chawla S, Fedenko A, Angeles C and Menendez LR: A meta-analysis of osteosarcoma outcomes in the modern medical era. Sarcoma 2012: 704872, 2012.

3. Ferrari S, Smeland S, Mercuri M, Bertoni F, Longhi A, Ruggieri P, Alvegard TA, Picci P, Capanna R, Bernini G, et al: Italian and scandinavian sarcoma groups: Neoadjuvant chemotherapy with high-dose Ifosfamide, high-dose methotrexate, cisplatin, and doxorubicin for patients with localized osteosarcoma of the extremity: A joint study by the Italian and Scandinavian Sarcoma Groups. J Clin Oncol 23: 8845-8852, 2005. 
4. Ai Z, Lu Y, Qiu S and Fan Z: Overcoming cisplatin resistance of ovarian cancer cells by targeting HIF-1-regulated cancer metabolism. Cancer Lett 373: 36-44, 2016.

5. Zhu H, Luo H, Zhang W, Shen Z, Hu X and Zhu X: Molecular mechanisms of cisplatin resistance in cervical cancer. Drug Des Devel Ther 10: 1885-1895, 2016.

6. Zou Z, Chang H, Li H and Wang S: Induction of reactive oxygen species: An emerging approach for cancer therapy. Apoptosis 22 : 1321-1335, 2017.

7. Abbotts R and Madhusudan S: Human AP endonuclease 1 (APE1): From mechanistic insights to druggable target in cancer. Cancer Treat Rev 36: 425-435, 2010.

8. Whitaker AM, Flynn TS and Freudenthal BD: Molecular snapshots of APE1 proofreading mismatches and removing DNA damage. Nat Commun 9: 399, 2018.

9. den Hartog G, Chattopadhyay R, Ablack A, Hall EH, Butcher LD, Bhattacharyya A, Eckmann L, Harris PR, Das S, Ernst PB and Crowe SE: Regulation of Rac1 and reactive oxygen species production in response to infection of gastrointestinal epithelia. PLoS Pathog 12: e1005382, 2016.

10. Angkeow P, Deshpande SS, Qi B, Liu YX, Park YC, Jeon BH, Ozaki M and Irani K: Redox factor-1: An extra-nuclear role in the regulation of endothelial oxidative stress and apoptosis. Cell Death Differ 9: 717-725, 2002.

11. Tell G, Fantini D and Quadrifoglio F: Understanding different functions of mammalian AP endonuclease (APE1) as a promising tool for cancer treatment. Cell Mol Life Sci 67: 3589-3608, 2010.

12. Bobola MS, Jankowski PP, Gross ME, Schwartz J, Finn LS, Blank A, Ellenbogen RG and Silber JR: Apurinic/apyrimidinic endonuclease is inversely associated with response to radiotherapy in pediatric ependymoma. Int J Cancer 129: 2370-2379, 2011.

13. Wang D, Xiang DB, Yang XQ, Chen LS, Li MX, Zhong ZY and Zhang YS: APE1 overexpression is associated with cisplatin resistance in non-small cell lung cancer and targeted inhibition of APE1 enhances the activity of cisplatin in A549 cells. Lung Cancer 66: 298-304, 2009.

14. Wu HH, Cheng YW, Chang JT, Wu TC, Liu WS, Chen CY and Lee H: Subcellular localization of apurinic endonuclease 1 promotes lung tumor aggressiveness via NF-kappaB activation. Oncogene 29: 4330-4340, 2010.

15. Al-Attar A, Gossage L, Fareed KR, Shehata M, Mohammed M, Zaitoun AM, Soomro I, Lobo DN, Abbotts R, Chan S, et al: Human apurinic/apyrimidinic endonuclease (APE1) is a prognostic factor in ovarian, gastro-oesophageal and pancreatico-biliary cancers. Br J Cancer 102: 704-709, 2010.

16. Demple B and Sung JS: Molecular and biological roles of Ape1 protein in mammalian base excision repair. DNA Repair (Amst) 4: 1442-1449, 2005

17. Cesaratto L, Codarin E, Vascotto C, Leonardi A, Kelley MR, Tiribelli $\mathrm{C}$ and Tell G: Specific inhibition of the redox activity of Ape1/Ref-1 by e3330 blocks Tnf- $\alpha$-induced activation of IL-8 production in liver cancer cell lines. PLoS One 8: e70909, 2013.

18. Jiang X, Shan J, Dai N, Zhong Z, Qing Y, Yang Y, Zhang S, Li C, Sui J, Ren T, et al: Apurinic/apyrimidinic endonuclease $1 \mathrm{regu}-$ lates angiogenesis in a transforming growth factor $\beta$-dependent manner in human osteosarcoma. Cancer Sci 106: 1394-1401, 2015

19. Lou D, Zhu L, Ding H, Dai HY and Zou GM: Aberrant expression of redox protein Ape1 in colon cancer stem cells. Oncol Lett 7: 1078-1082, 2014

20. Li M, Zhong Z, Zhu J, Xiang D, Dai N, Cao X, Qing Y, Yang Z, Xie J, Li Z, et al: Identification and characterization of mitochondrial targeting sequence of human apurinic/apyrimidinic endonuclease 1. J Biol Chem 285: 14871-14881, 2010.

21. Li MX, Shan JL, Wang D, He Y, Zhou Q, Xia L, Zeng LL, Li ZP, Wang G and Yang ZZ: Human apurinic/apyrimidinic endonuclease 1 translocalizes to mitochondria after photodynamic therapy and protects cells from apoptosis. Cancer Sci 103 $882-888,2012$

22. Li M, Vascotto C, Xu S, Dai N, Qing Y, Zhong Z, Tell G and Wang D: Human AP endonuclease/redox factor APE1/ref-1 modulates mitochondrial function after oxidative stress by regulating the transcriptional activity of NRF1. Free Radic Biol Med 53: 237-248, 2012

23. Yang ZZ, Li MX, Zhang YS, Xiang DB, Dai N, Zeng LL, Li ZP, Wang $G$ and Wang D: Knock down of the dual functional protein apurinic/apyrimidinic endonuclease 1 enhances the killing effect of hematoporphrphyrin derivative-mediated photodynamic therapy on non-small cell lung cancer cells in vitro and in a xenograft model. Cancer Sci 101: 180-187, 2010.
24. Fishel ML, Wu X, Devlin CM, Logsdon DP, Jiang Y, Luo M, He Y, Yu Z, Tong Y, Lipking KP, et al: Apurinic/apyrimidinic endonuclease/redox factor-1 (APE1/Ref-1) redox function negatively regulates NRF2. J Biol Chem 290: 3057-3068, 2015.

25. Wang D, Luo M and Kelley MR: Human apurinic endonuclease 1 (APE1) expression and prognostic significance in osteosarcoma: Enhanced sensitivity of osteosarcoma to DNA damaging agents using silencing RNA APE1 expression inhibition. Mol Cancer Ther 3: 679-686, 2004.

26. Fishel ML, He Y, Reed AM, Chin-Sinex H, Hutchins GD, Mendonca MS and Kelley MR: Knockdown of the DNA repair and redox signaling protein Ape1/Ref-1 blocks ovarian cancer cell and tumor growth. DNA Repair (Amst) 7: 177-186, 2008

27. Barchiesi A, Wasilewski M, Chacinska A, Tell G and Vascotto C: Mitochondrial translocation of APE1 relies on the MIA pathway. Nucleic Acids Res 43: 5451-5464, 2015.

28. Vascotto C, Cesaratto L, Zeef LA, Deganuto M, D'Ambrosio C, Scaloni A, Romanello M, Damante G, Taglialatela G, Delneri $\mathrm{D}$, et al: Genome-wide analysis and proteomic studies reveal APE1/Ref-1 multifunctional role in mammalian cells. Proteomics 9: 1058-1074, 2009.

29. Bokoch GM and Knaus UG: NADPH oxidases: Not just for leukocytes anymore! Trends Biochem Sci 28: 502-508, 2003.

30. Patil S, Bunderson M, Wilham J and Black SM: Important role for Rac1 in regulating reactive oxygen species generation and pulmonary arterial smooth muscle cell growth. Am J Physiol Lung Cell Mol Physiol 287: L1314-L1322, 2004.

31. Abo A, Pick E, Hall A, Totty N, Teahan CG and Segal AW: Activation of the NADPH oxidase involves the small GTP-binding protein p21rac1. Nature 353: 668-670, 1991.

32. Irani K, Xia Y, Zweier JL, Sollott SJ, Der CJ, Fearon ER, Sundaresan M, Finkel $\mathrm{T}$ and Goldschmidt-Clermont PJ: Mitogenic signaling mediated by oxidants in Ras-transformed fibroblasts. Science 275: 1649-1652, 1997.

33. Lőrincz AM, Szarvas G, Smith SM and Ligeti E: Role of Rac GTPase activating proteins in regulation of NADPH oxidase in human neutrophils. Free Radic Biol Med 68: 65-71, 2014.

34. Bokoch GM and Zhao T: Regulation of the phagocyte NADPH oxidase by Rac GTPase. Antioxid Redox Signal 8: 1533-1548, 2006.

35. Dan Dunn J, Alvarez LA, Zhang X and Soldati T: Reactive oxygen species and mitochondria: A nexus of cellular homeostasis. Redox Biol 6: 472-485, 2015.

36. Tomkinson AE, Bonk RT and Linn S: Mitochondrial endonuclease activities specific for apurinic/apyrimidinic sites in DNA from mouse cells. J Biol Chem 263: 12532-12537, 1988

37. Chappell NP, Teng PN, Hood BL, Wang G, Darcy KM, Hamilton CA, Maxwell GL and Conrads TP: Mitochondrial proteomic analysis of cisplatin resistance in ovarian cancer. J Proteome Res 11: 4605-4614, 2012.

38. Kulawiec M, Owens KM and Singh KK: Cancer cell mitochondria confer apoptosis resistance and promote metastasis. Cancer Biol Ther 8: 1378-1385, 2009.

39. Marrache S, Pathak RK and Dhar S: Detouring of cisplatin to access mitochondrial genome for overcoming resistance. Proc Natl Acad Sci USA 111: 10444-10449, 2014.

40. Joo HK, Lee YR, Park MS, Choi S, Park K, Lee SK, Kim CS, Park JB and Jeon BH: Mitochondrial APE1/Ref-1 suppressed protein kinase $\mathrm{C}$-induced mitochondrial dysfunction in mouse endothelial cells. Mitochondrion 17: 42-49, 2014.

41. Gatti L, Cassinelli G, Zaffaroni N, Lanzi C and Perego P: New mechanisms for old drugs: Insights into DNA-unrelated effects of platinum compounds and drug resistance determinants. Drug Resist Updat 20: 1-11, 2015.

42. Yang Z, Schumaker LM, Egorin MJ, Zuhowski EG, Guo Z and Cullen KJ: Cisplatin preferentially binds mitochondrial DNA and voltage-dependent anion channel protein in the mitochondrial membrane of head and neck squamous cell carcinoma: Possible role in apoptosis. Clin Cancer Res 12: 5817-5825, 2006.

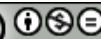

This work is licensed under a Creative Commons Attribution-NonCommercial-NoDerivatives 4.0 International (CC BY-NC-ND 4.0) License. 